\title{
Validation of malaria surveillance case reports: implications for studies of malaria risk
}

\author{
P A Phillips-Howard, J Mitchell, D J Bradley
}

\begin{abstract}
Study objective-The aim of the study was to investigate the quality of national malaria surveillance reports in the United Kingdom.
\end{abstract}

Design-Persons with malaria reported to the Malaria Reference Laboratory (MRL) in 1987 were contacted by post to verify existing records with respect to key variables. The MRL data set was then analysed for inaccuracies.

Setting-The study was confined to UK residents.

Participants -602 persons with malaria in 1987 responded (53\%).

Measurements and main results-Review of case reports showed few missing data except for duration of residence in the UK, detailed chemoprophylactic regimens, and compliance. There were more missing surveillance data in reports of ethnic minority groups, principally in dates of travel $(p=0.008)$ and chemoprophylaxis use $(p<0.0001)$. Patient recall in the survey was at variance with the surveillance reports in dates of travel and onset of infection, chemoprophylaxis use, and in compliance. Surveillance reports overestimated the number of days between leaving a malarious area and onset of symptoms (by 9 d for $P$ falciparum and by 24 $d$ for $P$ vivax), and underestimated the delay between onset and diagnosis of $P$ falciparum by $3 \mathrm{~d}$. Over $50 \%$ of patients who had recalled the use of cholorquine, proguanil, pyrimethamine/dapsone, and pyrimethamine had not been recorded as having taken these drugs on the surveillance reports. Reported compliance also differed between the two data sets.

Conclusions-It is recommended that research units test the quality of their surveillance data before embarking on analytical studies used to generate health policy guidelines.

Malaria is one of 33 notifiable diseases in the United Kingdom. By statute, clinical cases of malaria in each local authority are reported by the medical officers of environmental health to the Office of Population Censuses and Surveys (OPCS). The standard OPCS form for the notification of infectious disease or food poisoning is used to inquire about the date of onset and where malaria was contracted (abroad or induced). The Malaria Reference Laboratory of the Public Health Laboratory Service runs in parallel with this system, and has become the designated centre for the collation of national surveillance case reports. ${ }^{1}$ Malaria cases must be confirmed by the identification of Plasmodium parasites in the microscopic blood smear. Malaria cases are reported by multiple sources; $60^{\circ}{ }_{0}$ of notifications are automatically received when haematologists, physicians and microbiologists request the Malaria Reference Laboratory to confirm their slide diagnosis. The Malaria Reference Laboratory also receives reports of slides examined by the Public Health Laboratory Service network. Other reports are received from general practitioners, hospital physicians and medical officers of environmental health. The Malaria Reference Laboratory receives copies of the statistics of the OPCS and its staff cross check these against its own files for missing or incompatible reports. Notified cases are investigated individually. Any report received is followed up directly by sending the notifying physician a standard Malaria Reference Laboratory questionnaire to elicit information on the clinical and epidemiological features of each case. Hospital laboratories have a supply of these questionnaires, and most reporters seeking confirmation of diagnosis send a completed form along with each malaria slide. Physicians who do not respond to this questionnaire are sent a letter requesting their cooperation; another questionnaire and stamped addressed envelope are enclosed to facilitate their reply. Data from the questionnaires are transferred onto microcomputer using dBase III, enabling access to information for special investigations. This close collaboration has created a fully comprehensive surveillance system which generates information essential for health policy recommendations. Crude attack rates may be estimated when data on the number of travellers visiting malarious areas are available. ${ }^{2}$ When feasible, denominator data derived from travel statistics, and case data derived from national malaria surveillance, may be combined to define the efficacy of chemoprophylactic protection. ${ }^{3}$ This approach is more practical than independent cohort studies because extremely large cohort populations are needed in order to measure the relative efficacy of different chemoprophylactic regimens. ${ }^{4}$ If, however, routine surveillance records are to be used for research which has health policy implications, it is essential that their effectiveness be tested both in terms of the coverage of reporting and the quality of the data collated. This study addresses the quality of malaria surveillance data on UK residents, assessing the validity and completeness of the questionnaires received from reporting agents, 
and discusses the influence reporting errors may have on our understanding of risk factors associated with malaria.

\section{Methods}

RECRUITMENT AND FOLLOW UP OF SUBJECTS

Selection of cases-Case reports collected by the Malaria Reference Laboratory during 1987 were reviewed quarterly for retrospective follow up and from these, cases in UK residents were recruited for study. These were identified broadly as any individual who had resided in the UK prior to travelling. Cases whose residency was undetermined or who were suspected to be resident in the UK because they had a UK postal address, were also followed up. Survey by post was judged to be inexpedient for investigating deaths by proxy; the seven patients who died from malaria in 1987 were thus excluded.

Survey methods-A letter and questionnaire coded with the Malaria Research Laboratory number were sent to the reporting intermediaries. The letter explained that medical confidentiality prohibited us from corresponding directly with patients, and asked them to forward the items to their patients in the stamped envelopes provided. These were addressed if addresses were recorded on the Malaria Research Laboratory reports. This method was tested on $50 \mathrm{UK}$ residents diagnosed in July 1986; 42\% responded. Response rates were about $40 \%$ in Asians, $80 \%$ in white Caucasians and $25 \%$ in Africans. Based on this test, a simplified questionnaire with larger print was designed for use. For efficiency, batches of the final questionnaires were sent at three monthly intervals. Three hospitals in the final quarter requested that we correspond directly with their patients.

Scope of questions-Questions were designed in order to verify existing reports on variables that were usually well recorded like age, sex, ethnicity and reason for travel, and to complete missing information on inadequately answered questions, such as epidemiological dates, length of residence in the UK and patients' use of and compliance with named chemoprophylactic drugs. Additional data not routinely collected on Malaria Reference Laboratory report forms were collected and are presented elsewhere. ${ }^{5}$

\section{ANALYTICAL TECHNIQUES}

Methods-Biases in response were investigated using existing information on the Malaria Reference Laboratory reports. The computed Malaria Reference Laboratory data set was analysed to assess rates of completion of key variables and then cross checked against the corresponding survey data, case by case, to detect inconsistencies on the report forms. These were traced back to report forms to identify if any were associated with typographical errors in the Malaria Reference Laboratory.

Tests-Paired $t$ tests were performed to assess mean variation of ages and dates. Paired reports and survey data were compared using McNemars test $^{6}$ to determine which method achieved higher completion rates. Comparison of data between surveillance reports and survey data was conducted to measure the sensitivity, specificity and the predictive value of reports for identifying chemoprophylaxis use and compliance. Both tests were performed using conventional $2 \times 2$ contingency tables for each drug, enabling calculation of the proportion of reports imperfectly classified (see appendix). Data provided by patients during follow up were assumed to be the referent values. Youden's index ${ }^{6}$ provided a measure of the two error probabilities. The kappa coefficient ${ }^{7}$ was used to estimate the degree of random agreement expected to occur between surveillance reports and survey data. Significance was set at $p<0.05$ using $\chi^{2}$ or two tailed standard normal deviates (SND). Means refer to arithmetic means unless specified differently, with $95 \%$ confidence intervals (CI).

Definition of terms-Throughout this paper, unless otherwise indicated, Malaria Reference Laboratory case reports have been referred to as reports and case information elicited through follow up survey have been called survey data. In order to determine differences in health care patterns, cases were grouped by ethnicity; all residents whose origin stems from southern Asia, as identified by their name, ${ }^{8}$ were called Asians; those of African origin were grouped as Africans, again based on names; and the remainder were described as white Caucasians. Clearly, this is not a highly accurate classification system, but enabled a crude assessment of reporting differences between ethnic groups. In some analyses, reports on Asians and Africans were combined as ethnic minority groups. The chemoprophylaxis status of cases refers to the reported use of drugs by patients. Compliance with prophylaxis has been defined as the reported regular use of chemoprophylaxis, as prescribed. Full compliance describes cases who took their weekly or daily tablets on the allocated day, without missing any doses. These definitions are approximations as only blood concentrations can prove actual drug use.

\section{Results}

\section{RESPONSE RATES}

Of the 1816 reported malaria infections occurring in the United Kingdom in 1987, 1014 were reported in UK residents, and 802 in either foreigners or patients of unknown residency. Of the latter group, 536 were recruited for follow up because their names or addresses, or both, suggested possible UK residency. Of the known UK residents, 551 (54\%) responded to survey and of the suspected UK residents, $184(34 \%)$ responded. In the former group, $96 \%$ of responders satisfied the definition of UK residency and of those whose resident status was not clear, $17 \%$ of respondents were judged to be UK residents. In total, 604 responding cases were recruited for analysis, two $(0.3 \%)$ of whom were later rejected because they were duplicate reports. Response was not associated with age, sex or species of infection. Response rates in ethnic minority groups were lower than in white Caucasians, when ethnic origin was derived by name (SND 7.13, p $<0.0001$ ) or by birth place (SND 3.63, $p=0.00028$ ). Place of residence in the UK influenced response; proportionately less 
Table I Selected characteristics influencing the response of $U K$ residents with malaria to postal questionnaires

\begin{tabular}{|c|c|c|c|c|c|}
\hline \multirow{2}{*}{\multicolumn{2}{|c|}{ Selected variables }} & \multicolumn{3}{|c|}{ Response rates by ethnic group } & \multirow{3}{*}{$\begin{array}{c}\begin{array}{l}\text { Response } \\
\text { rate by } \\
\text { all groups }\end{array} \\
59 \\
56 \\
0.94 \\
0.36\end{array}$} \\
\hline & & \multirow{2}{*}{$\begin{array}{l}\text { White Caucasian } \\
71 \\
78 \\
1.27 \\
0.20\end{array}$} & \multirow{2}{*}{$\begin{array}{l}\text { Asian } \\
55 \\
51 \\
0.51 \\
0.60\end{array}$} & \multirow{2}{*}{$\begin{array}{l}\text { African } \\
47 \\
50 \\
0 \cdot 24 \\
0.81\end{array}$} & \\
\hline Species & $\begin{array}{l}P \text { falciparum }\left({ }^{0}{ }_{0}\right) \\
\text { Other species }\left({ }_{0}^{0}{ }_{0}\right) \\
\text { SND } \\
\text { p value }\end{array}$ & & & & \\
\hline Prophylaxis & $\begin{array}{l}\text { Taken }\left({ }^{\circ}{ }_{0}\right) \\
\text { Not taken }\left({ }^{\circ}{ }_{0}\right) \\
\text { SND } \\
\text { p value }\end{array}$ & $\begin{array}{l}74 \\
68 \\
1.03 \\
0.29\end{array}$ & $\begin{array}{l}57 \\
45 \\
2 \cdot 38 \\
0 \cdot 017\end{array}$ & $\begin{array}{l}60 \\
40 \\
2 \cdot 27 \\
0 \cdot 023\end{array}$ & $\begin{array}{l}67 \\
47 \\
5 \cdot 75 \\
<0.0001\end{array}$ \\
\hline Compliance & $\begin{array}{l}\text { Regular }\left({ }^{0}{ }_{0}\right) \\
\text { Irregular }\left({ }^{0}{ }_{0}\right) \\
\text { SND`} \\
\text { p value }\end{array}$ & $\begin{array}{l}79 \\
68 \\
1 \cdot 43 \\
0 \cdot 15\end{array}$ & $\begin{array}{l}53 \\
53 \\
0.02 \\
0.98\end{array}$ & $\begin{array}{l}78 \\
55 \\
1 \cdot 21 \\
0 \cdot 23\end{array}$ & $\begin{array}{l}73 \\
60 \\
2.06 \\
0.039\end{array}$ \\
\hline $\begin{array}{l}\text { County of } \\
\text { reporting }\end{array}$ & $\begin{array}{l}\text { London }\left({ }^{\circ}{ }_{0}\right) \\
\text { periphery }\left({ }^{\circ}{ }_{0}\right) \\
\text { SND } \\
\text { p value }\end{array}$ & $\begin{array}{l}72 \\
75 \\
0 \cdot 41 \\
0.68\end{array}$ & $\begin{array}{l}47 \\
53 \\
1 \cdot 19 \\
0 \cdot 23\end{array}$ & $\begin{array}{l}41 \\
68 \\
3 \cdot 33 \\
0 \cdot 0008\end{array}$ & $\begin{array}{l}50 \\
61 \\
3 \cdot 54 \\
0 \cdot 0004\end{array}$ \\
\hline
\end{tabular}

‡ SND = standard normal deviate (rounded)

replies were received from patients of London based reporters than those outside of London (table I). Where recorded, response was higher in UK residents who had used chemoprophylaxis (SND 5.75, p $<0.0001$ ). By controlling for ethnicity, response bias associated with chemoprophylaxis use diminished in white Caucasians but remained significant for Asian and African responders. The association between response and compliance was lost when controlling for ethnicity.

THE EFFICIENCY OF THE CASE REPORT FORMS The efficiency of surveillance reports was measured for nine key risk variables, to determine the proportion of reports with missing information and the variation occurring between information recorded on reports and patient recall.

\section{Age and sex}

Age and sex were recorded on $97^{\circ}$ of case reports, and only minor differences were identified with survey data. Variation occurred mainly when age was calculated from date of birth, on $64^{\circ} \%$ of occasions by the reporter and $36 \%$ by the Malaria Reference Laboratory. The mean difference between ages given on reports and from the patients during survey was not significant $(t=1 \cdot 6$, df $588, p=0 \cdot 11)$. Two thirds of cases were males and the mean age of cases was 31 years, varying little between ethnic groups or between sexes. Nine women stated they were pregnant at the time of infection; $6^{\circ}$ of the surveyed females of childbearing age; pregnancy had voluntarily been recorded on three Malaria Reference Laboratory reports.

\section{Country of birth}

Malaria Reference Laboratory reports specified country of birth in $502\left(83^{\circ}{ }_{0}\right)$ of cases, 211 of whom were born overseas. However, survey data revealed that $277\left(46^{\circ}{ }_{0}\right)$ of malaria patients were born overseas; $17^{\circ}$ o of white Caucasian cases, $62 \%$ of cases in residents of Asian origin, and $71 \%$ of cases of African origin. Missing information on country of birth was associated with ethnicity (SND 2.79, $\mathrm{p}=0.0053$ ). Of the 41 errors, over half the cases were UK born, but their birth place was recorded as Asia in 17 cases and Nigeria in five. Two were attributed to typographical error by the Malaria Reference Laboratory.
Duration of residence in the $U K$

Duration of residence in the UK by cases born abroad was recorded on 111 reports. Comparing dates from these reports with corresponding survey data, surveillance reports significantly underestimated duration of residence in the UK; $25\left(23^{\circ}{ }_{0}\right)$ of cases were defined as resident for less than three years, compared with nine $\left(8^{\circ}{ }_{0}\right)$ recorded by survey (SND 3.10, $p=0.0019$ ).

\section{Reason for travel}

Information on the reason for travel was absent on $70\left(12^{\circ}{ }_{0}\right)$ of reports. Missing data were strongly associated with ethnicity (SND 3.11, p = 0.0019). One in four reports documented a different reason for travel than that described by the patient during follow up. Errors in white Caucasians related to categories of work; of the 54 expatriate cases $31\left(57^{\circ}{ }_{0}\right)$ were correctly classified. Of the remainder, 12 were recorded as business travellers (implying a shorter duration abroad). Of the 84 business travellers, $25\left(30^{\circ}{ }_{0}\right)$ were wrongly grouped, of whom 15 had been recorded as holiday makers. Inconsistencies with Asian and African groups concerned definition; visiting friends or relatives and holiday were interchangeable, and foreign students residing in Britain were placed in one of many categories; foreign visitor, schoolchild, business, or visiting friends or relatives. A previously unrecognised group was immigrant children who received part time schooling abroad.

\section{Country of visit}

The country in which malaria was acquired was recorded on $96^{\circ}{ }_{0}$ of reports, with Asian reports the least complete. Less than $2^{\circ}{ }^{\circ}$, documented the wrong country. Errors mainly arose when more than one country was visited. This occurred in $\mathbf{4 0}$ reports of white Caucasians $\left(17^{\circ}{ }^{\circ}\right.$ of all cases in this group); half of these had been adequately documented on report forms but in order to conform with coding rules during computing only the principal country or the region had been recorded.

\section{Epidemiological dates}

Return and onset of symptoms-The dates of departure from malarious countries were missing from 107 reports $\left(18^{\circ}{ }_{0}\right)$ and significantly more were missed on reports of cases in ethnic 
minorities (SND $2.65 \mathrm{p}=0.008$ ). Of the 492 reported dates, $294(60 \%)$ differed from the patients' recall of dates, and five of these were attributed to Malaria Reference Laboratory error. Of the inaccurate dates, $156(53 \%)$ resulted from incomplete dates, of which $119(40 \%)$ recorded information to within a month. These dates constituted either the month of return only, or of a period (such as "three weeks ago") which reduced accuracy because Malaria Reference Laboratory reports were undated. On 17 occasions the year of return was the only date given. The Malaria Reference Laboratory currently document midmonth (or mid-year!) estimates for incomplete reports. Where precise dates were given, 198 of $336(59 \%)$ concurred with the patients' recall of dates to within a few days, and $81(24 \%)$ to within one week. Dates of onset were more precise; 541 $(90 \%)$ of reports were complete with $192(36 \%)$ dates differing from the patients. Of these, 38 $(7 \%)$ had provided the date of onset of symptoms which had occurred overseas, a feature mainly associated with white Caucasians (SND 3.77, $\mathrm{p}=0.0002$ ). Although there were gross errors in some reporting dates (range -330 to +268 days for date of onset) the mean difference between Malaria Reference Laboratory reports and survey data, for dates of return ( $t=0.0035$, df 366, SEM 15.9) and for dates of onset ( $t=0.005$, df 519, SEM 31) were not statistically significant.

Latency periods-Latency periods were defined as the mean number of days between return and onset of symptoms. For $P$ falciparum infections the arithmetic mean values were $19(95 \% \mathrm{CI}, 10)$ $\mathrm{d}$ based on reports and $10(1) \mathrm{d}$ based on survey data (SND 1.91, p = 0.056). Geometric means provided a truer estimate of latency periods of $P$ falciparum because data were skewed, with a long right tail. Geometric means were 7 (1) d based on Malaria Reference Laboratory reported dates and 5 (1) d based on survey data. Comparison by means of aggregated logarithmically transformed data thus tended to minimise extreme values. Arithmetic mean periods for $P$ vivax infections were 169 (22) d based on Malaria Reference Laboratory reports and 145 (14) d based on survey data (SND 1.79, $\mathrm{p}=0.073$ ). The distribution of $P$ vivax infections were also skewed, but in the opposite direction to $P$ falciparum. Thus squared transformation provided a more representative mean. Transformed mean latency periods were 239 (48) d using Malaria Reference Laboratory reports and 497 (54) d using survey data.

Onset of symptoms to diagnosis-Nine Malaria Reference Laboratory reports recorded the date of diagnosis before the date of onset. The mean delay in diagnosing $P$ falciparum infections after onset of symptoms was 11.5 (2.8) d using Malaria Reference Laboratory reports and $9.8(2.5) \mathrm{d}$ using survey data. The mean delay in diagnosis by Malaria Reference Laboratory reports fell to $7 \cdot 2$ $(2 \cdot 2) \mathrm{d}$ when overseas cases and cases with midmonth estimations for unspecified dates of onset were excluded. The mean underestimated delay of $2.6 \mathrm{~d}$ is of clinical importance; however, in statistical terms this difference was not significant (SND 0.067, $\mathrm{p}=0.95$ ). Mean delays in diagnosing $P$ vivax infections were $12 \cdot 2(2 \cdot 8) \mathrm{d}$ using Malaria Reference Laboratory reports and 33.5 (9) d using survey data. Removing overseas infections and cases with mid-month estimation of onset, this value dropped to 8.9 (2) d. The underestimated mean difference in diagnostic delay between Malaria Reference Laboratory reports and survey data was $24.6 \mathrm{~d}$, but this was not statistically significant (SND 1·14, $\mathrm{p}=0 \cdot 25$ ).

\section{Chemoprophylactic drug use}

Use or absence of use of a chemoprophylactic drug, described as the patients' chemoprophylaxis status, was recorded on $472(78 \%)$ reports (table II). Missing data were strongly associated with ethnicity (SND 4.95, $\mathrm{p}<0.0001)$. Of those recorded, $277(59 \%)$ patients were said to have taken chemoprophylaxis, and within this group, 221 $(80 \%)$ reports named the chemoprophylactic drug but the exact dose and regimen was only recorded in $22(8 \%)$. The majority of reports omitting named chemoprophylaxis were in Asian cases (SND 5.15, p < 0.0001).

\section{THE QUALITY OF REPORTED \\ CHEMOPROPHYLACTIC USE \\ Chemoprophylaxis}

Provision of data- McNemar's test showed that the follow up of patients by survey provided significantly more information on drug use than had the routine Malaria Reference Laboratory surveillance report forms (table II). By survey, $200(90 \%)$ of cases using prophylaxis stated the name, dose and regimen, compared with 22 $(10 \%)$ recorded on report forms. The chemoprophylactic drug recalled as used by the patients differed substantially from that recorded on the surveillance report form (table III).

Predictive value of reports-Analysis of the predictive value of Malaria Reference Laboratory surveillance reports determined that there was an $81 \%$ probability that an individual case identified as taking chemoprophylaxis was truly using a drug, but values varied for different drugs (table IV). The likelihood of documenting an individual's use of Maloprim and chloroquine was

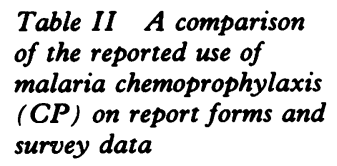

\begin{tabular}{|c|c|c|c|c|c|c|c|c|c|c|c|c|}
\hline & \multicolumn{3}{|c|}{$\begin{array}{l}\text { CP status } \\
\text { Data on report forms }\end{array}$} & \multicolumn{3}{|c|}{$\begin{array}{l}\text { CP taken } \\
\text { Data on report forms }\end{array}$} & \multicolumn{3}{|c|}{$\begin{array}{l}\text { Named CP } \\
\text { Data on report forms }\end{array}$} & \multicolumn{3}{|c|}{$\begin{array}{l}\text { Dose/regimen } \\
\text { Data on report forms }\end{array}$} \\
\hline & $\begin{array}{l}\text { Stated } \\
+\end{array}$ & $\begin{array}{l}\text { Not } \\
\text { stated } \\
-\end{array}$ & Total & $\begin{array}{l}\text { Stated } \\
\text { yes } \\
+\end{array}$ & $\begin{array}{l}\text { Stated } \\
\text { no } \\
-\end{array}$ & Total & $\begin{array}{l}\text { Named } \\
+\end{array}$ & $\begin{array}{l}\text { Not } \\
\text { named } \\
-\end{array}$ & Total & $\begin{array}{l}\text { Stated } \\
+\end{array}$ & $\begin{array}{l}\text { Not } \\
\text { stated } \\
-\end{array}$ & Total \\
\hline $\begin{array}{r}\text { Survey }+ \\
-\end{array}$ & $\begin{array}{r}472 \\
0\end{array}$ & $\begin{array}{r}127 \\
3\end{array}$ & $\begin{array}{r}599 \\
3\end{array}$ & $\begin{array}{r}255 \\
22\end{array}$ & $\begin{array}{r}47 \\
148\end{array}$ & $\begin{array}{l}302 \\
170\end{array}$ & $\begin{array}{r}198 \\
23\end{array}$ & $\begin{array}{l}32 \\
24\end{array}$ & $\begin{array}{r}230 \\
47\end{array}$ & $\begin{array}{r}21 \\
1\end{array}$ & $\begin{array}{c}179 \\
20\end{array}$ & $\begin{array}{r}200 \\
21\end{array}$ \\
\hline Total & 472 & 130 & 602 & 277 & 195 & 472 & 221 & 56 & 277 & 22 & 199 & 221 \\
\hline $\begin{array}{l}\chi^{2} \\
\mathbf{p} \text { values }\end{array}$ & \multicolumn{3}{|c|}{$\begin{array}{l}125 \\
<0.0001\end{array}$} & \multicolumn{3}{|c|}{$\begin{aligned} & 8.35 \\
< & 0.005\end{aligned}$} & \multicolumn{3}{|c|}{$\begin{array}{l}1 \cdot 16 \\
\text { NS }\end{array}$} & \multicolumn{3}{|c|}{$\begin{array}{l}174 \\
<0.0001\end{array}$} \\
\hline
\end{tabular}

McNemar's test with paired reports only, thus $\mathrm{n}=$ report forms with information recorded. 
Table III Chemoprophylactic drug use recorded on report forms compared with patient recall during survey

\begin{tabular}{|c|c|c|c|c|c|c|c|c|c|c|c|c|c|c|c|c|c|c|c|c|c|}
\hline & \multicolumn{21}{|c|}{ Data recorded on report forms } \\
\hline & \multicolumn{3}{|c|}{ All CP taken } & \multicolumn{3}{|c|}{ Chloroquine (CQ) } & \multicolumn{3}{|c|}{ CQ-proguanil } & \multicolumn{3}{|c|}{ Proguanil } & \multicolumn{3}{|c|}{ Maloprim-CQ } & \multicolumn{3}{|c|}{ Maloprim } & \multicolumn{3}{|c|}{ Pyrimethamine } \\
\hline & + & - & $\overline{\text { Total }}$ & + & - & $\overline{\text { Total }}$ & + & - & $\overline{\text { Total }}$ & + & - & $\overline{\text { Total }}$ & + & - & $\overline{\text { Total }}$ & + & - & $\overline{\text { Total }}$ & + & - & Total \\
\hline $\begin{array}{l}\text { Data recorded } \\
\text { on survey }\end{array}$ & $\begin{array}{l}+\quad 334 \\
-\quad 47\end{array}$ & $\begin{array}{r}70 \\
148\end{array}$ & $\begin{array}{l}404 \\
195\end{array}$ & $\begin{array}{l}33 \\
62\end{array}$ & $\begin{array}{r}39 \\
247\end{array}$ & $\begin{array}{r}72 \\
309\end{array}$ & $\begin{array}{l}48 \\
39\end{array}$ & $\begin{array}{r}14 \\
280\end{array}$ & $\begin{array}{r}62 \\
319\end{array}$ & $\begin{array}{l}15 \\
34\end{array}$ & $\begin{array}{r}9 \\
323\end{array}$ & $\begin{array}{r}24 \\
357\end{array}$ & $\begin{array}{l}20 \\
18\end{array}$ & $\begin{array}{r}4 \\
339\end{array}$ & $\begin{array}{r}24 \\
357\end{array}$ & $\begin{array}{r}8 \\
10\end{array}$ & $\begin{array}{r}10 \\
353\end{array}$ & $\begin{array}{r}18 \\
363\end{array}$ & $\begin{array}{r}9 \\
16\end{array}$ & $\begin{array}{r}1 \\
355\end{array}$ & $\begin{array}{r}10 \\
371\end{array}$ \\
\hline Total & 381 & 218 & 599 & 95 & 286 & 381 & 87 & 294 & 381 & 49 & 332 & 381 & 38 & 343 & 381 & 18 & 363 & 381 & 25 & 356 & 381 \\
\hline
\end{tabular}

Table IV Measures of the reliability of report forms to identify chemoprophylactic use by UK residents with malaria in 1987. Values are percentages

\begin{tabular}{|c|c|c|c|c|c|c|c|c|}
\hline \multirow[b]{2}{*}{ Chemoprophylactics } & \multicolumn{2}{|c|}{$\begin{array}{l}\text { Predictive } \\
\text { values }\end{array}$} & \multirow[t]{2}{*}{$1-B$} & \multirow[t]{2}{*}{$1-x$} & \multicolumn{2}{|c|}{$\begin{array}{l}\text { False } \\
\text { rates }\end{array}$} & \multirow[t]{2}{*}{$\begin{array}{l}\text { Youden's } \\
\text { index }\end{array}$} & \multirow[t]{2}{*}{$\begin{array}{l}\text { Kappa } \\
\text { coefficient }\end{array}$} \\
\hline & + & - & & & B & $\mathbf{x}$ & & \\
\hline $\begin{array}{l}\text { Chloroquine (CQ) } \\
\text { Proguanil } \\
\text { Maloprim } \\
\text { Pyrimethamine } \\
\text { CQ-proguanil } \\
\text { Maloprim-CQ }\end{array}$ & $\begin{array}{l}46 \\
63 \\
44 \\
90 \\
77 \\
83\end{array}$ & $\begin{array}{l}80 \\
90 \\
97 \\
96 \\
88 \\
95\end{array}$ & $\begin{array}{l}35 \\
31 \\
44 \\
36 \\
55 \\
53\end{array}$ & $\begin{array}{r}86 \\
97 \\
97 \\
100 \\
95 \\
99\end{array}$ & $\begin{array}{l}65 \\
69 \\
56 \\
64 \\
45 \\
47\end{array}$ & $\begin{array}{r}14 \\
3 \\
3 \\
0 \\
5 \\
1\end{array}$ & $\begin{array}{l}21 \\
28 \\
42 \\
36 \\
50 \\
51\end{array}$ & $\begin{array}{l}23 \\
36 \\
42 \\
50 \\
56 \\
62\end{array}$ \\
\hline All & 83 & 76 & 88 & 68 & 12 & 32 & 56 & 57 \\
\hline
\end{tabular}

Calculations derived from table III (formulas given in appendix)

low. The probability of defining a case who took no chemoprophylaxis was lower overall but was higher for each specific drug measured. This was because $20 \%$ of reports stated "yes" for the name of the chemoprophylactic drug. The proportion of cases identified through reports as drug users for each chemoprophylactic was underestimated; $50 \%$ or more of patients stating during survey that they had used chloroquine, proguanil, Maloprim or pyrimethamine were not recorded as such on surveillance reports. The proportion of cases identified by surveillance as truly taking no drugs was more accurate; but chloroquine use was overestimated by $14 \%$. No cases were falsely recorded as taking pyrimethamine but many were missed. Measurement of the sum of the two error probabilities by Youden's index suggested that $57 \%$ of Malaria Reference Laboratory reports accurately recorded chemoprophylaxis status, and that misclassification of drugs was highest in . cases taking monoprophylaxis and lowest with multiple prophylaxis.

Random agreement-Both reports and patients' recall were judged to be imperfect and subject to error. The expected chance agreement that could have occurred, according to the kappa coefficient, ranged between $63 \%$ and $90 \%$ (table IV). The true agreement for each drug would thus be substantially lower if random agreement were taken into account.

\section{Compliance}

Few data were available to compare patients recalled compliance with that recorded on report forms. Of the 277 reports which indicated chemoprophylaxis was used, $118(43 \%)$ did not record patients' compliance and of the 159 that did, 112 reports agreed with patient recall of compliance. Only 53 of these, however, concurred for the same drug (table V).

Predictive value of reports-A comparison between Malaria Reference Laboratory surveillance reports and survey data indicated that the probability of correctly defining full compliance in an individual case whose compliance status with chemoprophylaxis had been defined was $85^{\circ}$ o , and for correctly defining incomplete compliance was $65^{\circ}$ o (table VI). The proportion of cases truly determined as compliant was $69 \%$ and the proportion truly identified as not compliant was higher at $82^{\circ}{ }_{0}$. Thirty one percent of cases were falsely described as noncompliant. Values differed according to the chemoprophylactic drug; reports underestimated compliance in chloroquine-proguanil users by $40 \%$ and in Maloprim-chloroquine users by $29^{\circ}{ }_{0}$. Conversely, compliance in proguanil users was overestimated by $33^{\circ}{ }_{0}$. Youden's index indicated that misclassification of compliance was lowest in chloroquine users and that for Maloprim estimates were no better than if cases had been allocated by random means. The value of the Youdens index for pyrimethamine was between -1 and 0 , suggesting that the Malaria Reference Laboratory was screening for something other than the compliance of pyrimethamine users.

Random agreement-The compliance status of only 53 case reports could be compared. The degree of random agreement expected to occur between reports and survey data was high for most drugs (table VI). No kappa values could be calculated for pyrimethamine and Maloprim.

Table $V$ Compliance with chemoprophylaxis recorded on report forms compared with patient recall during survey

\begin{tabular}{|c|c|c|c|c|c|c|c|c|c|c|c|c|c|c|c|c|c|c|c|c|c|c|}
\hline & \multicolumn{22}{|c|}{ Data recorded on report forms } \\
\hline & \multicolumn{4}{|c|}{ Compliance all } & \multicolumn{3}{|c|}{ Chloroquine (CQ) } & \multicolumn{3}{|c|}{ CQ-proguanil } & \multicolumn{3}{|c|}{ Proguanil } & \multicolumn{3}{|c|}{ Maloprim-CQ } & \multicolumn{3}{|c|}{ Maloprim } & \multicolumn{3}{|c|}{ Pyrimethamine } \\
\hline & + & & - & Total & + & - & $\overline{\text { Total }}$ & + & - & Total & + & - & Total & + & - & $\overline{\text { Total }}$ & $\bar{t}$ & - & Total & + & - & Total \\
\hline $\begin{array}{l}\text { Data recorded } \\
\text { on survey }\end{array}$ & $\begin{array}{l}+5 \\
-2\end{array}$ & & $\begin{array}{l}10 \\
46\end{array}$ & $\begin{array}{l}66 \\
71\end{array}$ & $\begin{array}{r}10 \\
3\end{array}$ & $\begin{array}{l}1 \\
5\end{array}$ & $\begin{array}{r}11 \\
8\end{array}$ & $\begin{array}{l}9 \\
6\end{array}$ & $\begin{array}{l}3 \\
9\end{array}$ & $\begin{array}{l}12 \\
15\end{array}$ & $\begin{array}{l}4 \\
0\end{array}$ & $\frac{1}{2}$ & $\begin{array}{l}5 \\
2\end{array}$ & $\begin{array}{l}5 \\
2\end{array}$ & $\begin{array}{l}1 \\
3\end{array}$ & $\begin{array}{l}6 \\
5\end{array}$ & $\begin{array}{l}1 \\
0\end{array}$ & $\begin{array}{l}2 \\
0\end{array}$ & $\begin{array}{l}3 \\
0\end{array}$ & $\begin{array}{l}5 \\
2\end{array}$ & $\begin{array}{l}0 \\
0\end{array}$ & $\begin{array}{l}5 \\
2\end{array}$ \\
\hline Total & 8 & & 66 & 137 & 13 & 6 & 19 & 15 & 12 & 27 & 4 & 3 & 7 & 7 & 4 & 11 & 1 & 2 & 3 & 7 & 0 & 7 \\
\hline
\end{tabular}


Table VI Measures of the reliability of report forms to identify correct compliance status with chemoprophylaxis of UK residents with malaria in 1987. Values are percentages

\begin{tabular}{|c|c|c|c|c|c|c|c|c|}
\hline \multirow[b]{2}{*}{ Chemoprophylactics } & \multicolumn{2}{|c|}{$\begin{array}{l}\text { Predictive } \\
\text { values }\end{array}$} & \multirow[t]{2}{*}{$1-B$} & \multirow[t]{2}{*}{$1-X$} & \multicolumn{2}{|c|}{$\begin{array}{l}\text { False } \\
\text { rates }\end{array}$} & \multirow[t]{2}{*}{$\begin{array}{l}\text { Youden's } \\
\text { index }\end{array}$} & \multirow[t]{2}{*}{$\begin{array}{l}\text { Kappa } \\
\text { coefficient }\end{array}$} \\
\hline & + & - & & & B & $\mathbf{x}$ & & \\
\hline $\begin{array}{l}\text { Chloroquine (CQ) } \\
\text { Proguanil } \\
\text { Maloprim } \\
\text { Pyrimethamine } \\
\text { CQ-proguanil } \\
\text { Maloprim-CQ }\end{array}$ & $\begin{array}{r}91 \\
80 \\
33 \\
100 \\
75 \\
83\end{array}$ & $\begin{array}{r}63 \\
100 \\
0 \\
0 \\
60 \\
60\end{array}$ & $\begin{array}{r}77 \\
100 \\
100 \\
71 \\
60 \\
71\end{array}$ & $\begin{array}{r}83 \\
67 \\
0 \\
0 \\
75 \\
75\end{array}$ & $\begin{array}{r}23 \\
0 \\
0 \\
29 \\
40 \\
29\end{array}$ & $\begin{array}{r}17 \\
33 \\
100 \\
0 \\
25 \\
25\end{array}$ & $\begin{array}{r}60 \\
67 \\
0 \\
- \\
35 \\
46\end{array}$ & $\begin{array}{r}55 \\
70 \\
- \\
\overline{34} \\
44\end{array}$ \\
\hline All & 85 & 65 & 69 & 82 & 31 & 18 & 51 & 49 \\
\hline
\end{tabular}

Calculations derived from table $\mathrm{V}$ (formulas given in appendix)

NB: only cases whose compliance status was documented have been used in these calculations

\section{Discussion}

Follow up of patients was used to test the quality of routine surveillance reports of imported malaria in the UK. Information from patient recall suggested that the standard of reports completed by doctors and other health professionals in the UK is, in general, very high. Of the nine key variables studied individually, six were recorded accurately on $80 \%$ or more of the surveillance reports, although only half of all reports were complete for every variable. The use of patient recall to validate surveillance reports does, however, require caution. First, response to follow up in known British residents was 54\%. Inadequate postal addresses, the movement of expatriate groups and false classification of foreign visitors may have reduced response in all groups. Second, use of patient recall as the referent value for chemoprophylactic drug use cannot be accepted without verification. The time lag between the exposure to infection and completion of the survey questionnaire may have caused recall bias. The lag combines the latency period of infection, the delay of diagnosis and up to three months lapse between reporting and follow up. Accordingly, time related recall bias would be greatest in cases with $P$ vivax infections. However, data pertaining to efficacy studies focus principally on $P$ falciparum infections. Additionally, it may be assumed that a serious and life threatening event will be recalled with greater clarity than minor ailments. Closed questions on the survey forms provided patients with options of "cannot remember" and "don't know the name", if they were unable to remember information; thus $56(15 \%)$ of chemoprophylactic users could not recall their prophylaxis, and 11 $(3 \%)$ did not remember the doses. Eighty nine percent of the former and $28 \%$ of the latter were Asians with $P$ vivax infections. Nevertheless, it remains inevitable that misclassification of chemoprophylaxis may have occurred in a proportion of patients. Reported compliance with chemoprophylaxis similarly lacks precision since subjective opinions concerning absolute regularity differ. Various survey questions asked for information on compliance and enabled us to assess the accuracy of these data more thoroughly.

This validation study identified three major flaws associated with data reported through passive surveillance of malaria in the UK. Reporters recorded less information on risk factors associated with malaria in ethnic minority groups, data reported on the use of chemoprophylaxis in all groups lacked precision, and reporters generally underestimated diagnostic delays. Health care provision for ethnic minority groups is considered to be inferior to that provided for other groups of society but cannot easily be quantified. ${ }^{9}$ Our survey data support this conjecture; the quality of information on Asians and African cases, gathered through the surveillance process, was lower for many of the variables tested. Reasons for this difference are not clear; a reduction in the quality of epidemiological dates would be expected for $P$ vivax infections with long latency periods, but other variables should be comparable between racial groups.

While personal information on cases has been shown to be of high quality, data on chemoprophylactic use and compliance appear to have been less completely documented. Historically, little emphasis was placed on the reporting of the chemoprophylactic status of patients; before the advent of resistant strains of $P$ falciparum, malaria could be assumed to result when chemoprophylaxis was neglected. The results of this study imply that some reporting agents may still be assuming that patients with malaria became infected because they took no chemoprophylaxis. Over time, it is probable that increasing numbers of non-immune travellers will become exposed to drug resistant strains of $P$ falciparum. It thus becomes essential that their chemoprophylactic status is accurately recorded and reporting agents are urged to be attentive to this need.

Deaths associated with $P$ falciparum infections in non-immune travellers have been attributed to the absence of chemoprophylaxis and to protracted delay between onset of symptoms and diagnosis. ${ }^{10}$ The efficacy of chemoprophylaxis for preventing deaths in travellers with chloroquine resistant $P$ falciparum has, however, recently been questioned. ${ }^{11}$ Measures calculated from the data imply that the relative risks for survivors and fatalities related to chemoprophylactic use and to diagnostic delays using surveillance data may be spurious. While the recording of the onset of symptoms abroad is logical, these cases require additional investigation to establish whether the condition overseas was related to the malaria attack treated on return to the UK. Symptoms may have been either of a former, resolved infection, or part of the same infection which may have been inadequately treated or which occurred just prior to return. Clearly, an infection that was inadequately treated abroad requires particular attention, to establish whether the species of infection was a resistant strain of $P$ falciparum. However, inclusion of such cases in the measurement of diagnostic delays within the UK causes bias. The interval between onset and 
diagnosis in those who die may be researched individually. If it is compared with an over long estimate of mean delay before diagnosis in survivors (as would result from surveillance reports), the role of delayed diagnosis would be denigrated and would lessen the perceived need for patients to seek, and receive, prompt and appropriate treatment. Conversely if the mean delay was underestimated it would falsely show that the majority of patients receive timely care, implying that health care measures are currently adequate. Continuous surveillance of a nonendemic communicable disease, at national level, depends on strong collaborative links with health professionals. In the UK the general calibre of reporting malaria is high, despite the fact that some reporters rarely encounter a patient with malaria. It is anticipated that with time, there will be increased recognition of the value of surveillance systems and that this will, in turn, further enhance reporting standards. No system, however, will ever be perfect and these results suggest that research units test the quality of surveillance data before embarking upon analytic studies used to generate health policy guidelines.

The haematologists, microbiologists, general practitioners, medical officers of environmental health, and physicians who participated in this study are acknowledged for their valuable assistance; the patients for providing us with detailed responses; and the Malaria Reference Laboratory staff for enabling access to reports. We are very grateful to Dr Brian Southgate, Dr Kent Campbell and Dr Ronald Mann for their critical comments on the manuscript. PAPH was supported by the Leverhulme Trust and the Malaria Action Programme of WHO.

\section{Appendix}

FORMULAS FOR ANALYSES

(a) Contingency tables

\begin{tabular}{|c|c|c|c|}
\hline & & & Total \\
\hline & + & - & \\
\hline MRL & $\mathbf{a}$ & b & $a+b$ \\
\hline-1 & c & d & $c+d$ \\
\hline Total & $a+c$ & $b+d$ & $\mathbf{N}$ \\
\hline
\end{tabular}

Predictive value $+a / a+b$

Predictive value - d/c $+d$

Sensitivity $(1-B) a / a+c$

Specificity $(1-X) d / b+d$

False - rate (B) $c / a+c$

False + rate (X) b/b + d

Youden's index $(1-B)-X$

\section{(b) Kappa coefficient}

Observed - expected

1 - expected

Expected $=\frac{(a+b)(a+c)+(c+d)(b+d)}{N^{2}}$

Observed $=\mathbf{a}+\mathrm{d} / \mathrm{N}$

1 Bruce-Chwatt LJ. Malaria Reference Laboratory $\mathrm{Br} \mathrm{Med} \mathcal{F}$ 1973; ii: 181.

2 Phillips-Howard PA, Breeze E, Lakin C, Bradley DJ. Short term travel to malarious areas; malaria risk in UK travellers. Trav Med Internat 1988; 6: 51-60.

3 Phillips-Howard PA. The efficacy of drug prophylaxis. $f R$ Soc Med 1989; 82 (Suppl 17): 23-9.

4 Fogh S, Schapira A, Bygbjerg IC et al. Malaria chemoprophylaxis in travellers to east Africa: a comparative prospective study of chloroquine plus proguanil with chloroquine plus sulfadoxine-pyrimethamine $\mathrm{Br}$ Med $\mathcal{F}$ 1988; 296: 820-2.

5 Phillips-Howard PA. The epidemiology of malaria in Britain London: University of London, 1988. PhD thesis.

6 Armitage P, Berry G. Statistical methods in medical research, 2nd edition. Oxford: Blackwell Scientific Publications, 1987.

7 Kelsey JL, Thompson WD, Evans AS. Methods in observational epidemiology. New York: Oxford University Press, 1986

8 Nicoll A, Bassett K, Ulijasek SJ. The use of Asian names for identification of ethnic group. $\mathcal{f}$ Epidemiol Community Health 1986; 40: 364-8.

9 Townsend P, Davidson N. Inequalities in health: the Black report. London: Penguin Books, 1984.

10 Lobel HO, Campbell CC, Roberts JM. Fatal malaria in US civilians. Lancet 1985; i: 873.

11 Ellis C. Death despite malaria prophylaxis $\mathrm{Br} \mathrm{Med} \mathcal{O}$ 1988; 296: 952. 